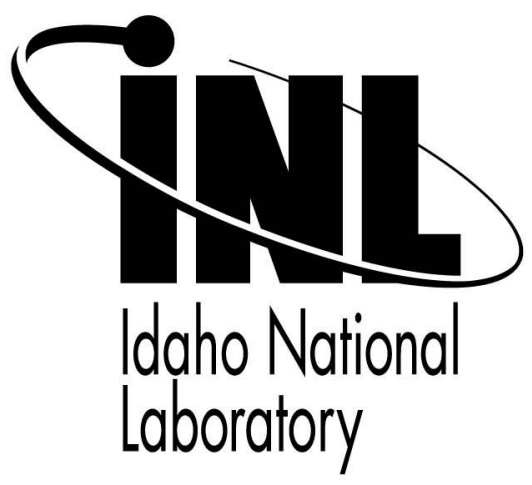

\title{
Recruiting Future Engineers Through Effective Guest Speaking in Elementary School Classrooms
}

\section{Meeting the Growing Demand for Engineers and Their Educators 2010 - 2020 International Summit}

\author{
Kevin L. Young
}

November 2007

This is a preprint of a paper intended for publication in a journal or proceedings. Since changes may be made before publication, this preprint should not be cited or reproduced without permission of the author. This document was prepared as an account of work sponsored by an agency of the United States Government. Neither the United States Government nor any agency thereof, or any of their employees, makes any warranty, expressed or implied, or assumes any legal liability or responsibility for any third party's use, or the results of such use, of any information, apparatus, product or process disclosed in this report, or represents that its use by such third party would not infringe privately owned rights. The views expressed in this paper are not necessarily those of the United States Government or the sponsoring agency. 



\begin{abstract}
In this paper, the author describes how engineers can increase the number of future engineers by volunteering as guest speakers in the elementary school classroom. The paper is divided into three main subjects. First, the importance of engineers speaking directly with young students is discussed. Next, several best practice techniques for speaking with young students are described. Finally, information on getting started as a guest speaker is presented, and a list of resources available to guest speakers is provided. The guest engineer speaking to an elementary school audience (ages 6-11) performs a critical role in encouraging young students to pursue a career in engineering. Often, he or she is the first engineer these students meet in person, providing a crucial first impression of the engineering career field and a positive visual image of what an engineer really looks like. A dynamic speaker presenting a well-delivered talk creates a lasting, positive impression on students, influencing their future decisions to pursue careers in engineering. By reaching these students early in life, the guest speaker will help dispel the many prevailing stereotypes about engineers which discourage so many students, especially young women, from considering this career. The guest speaker can ensure young students gain a positive first impression of engineers and the engineering career field by following some best practice techniques in preparing for and delivering their presentation. The author, an electrical engineer, developed these best practice techniques over the past 10 years while presenting over 350 talks on engineering subjects to elementary school students as a volunteer speaker with the U.S. Department of Energy, Idaho National Laboratory's Speakers Bureau. Every engineer can make a meaningful contribution toward reversing the predicted shortfall of future engineers by volunteering to speak with young students at the elementary school level. Elementary school teachers typically have a limited education in engineering and are eager to have career engineers speak with their students. As an engineer, there are many opportunities to get involved with guest speaking at the elementary school level. If you have a young child, start by meeting with her or his teacher and volunteering to give a presentation on engineering to the class. Many organizations have formal speakers bureaus. If your organization does not have one, consider starting one. There are several excellent resources on the Internet, such as the IEEE Center for Pre-University Engineering Education's TryEngineering.org Web site. This site is designed for young students, teachers and parents, giving information on engineering careers and engineering activities the guest speaker can use to prepare a dynamic and informative presentation. Young students who have experienced a positive interaction with an engineer are more likely to pursue a career in engineering. Effective guest speaking by engineers in elementary school classrooms today will increase the likelihood these young students will become the desperately needed engineers of our future.
\end{abstract}




\section{INTRODUCTION}

Engineers play a vital role in creating the advanced technologies and complex systems prevalent in modern life, yet current trends indicate a future shortage of engineers. An increasing number of studies have expressed concern about the projected widening gap between the demand for engineers and the number of students graduating with engineering degrees. This growing gap within the United States, as well as most other western countries, is expected to result in declining technological advancement, reduced corporate growth, reduced economic development and a reduced general standard of living [1]. If the United States and other western countries are to maintain their current level of innovation and technological advancements, we must find ways of generating more engineers.

The process of generating engineers is occasionally referred to as a "pipeline" with elementary school students entering at one end and college graduates with engineering degrees coming out the other end. To enter and move successfully through the pipeline, students must gain an awareness of engineering careers, develop intent to become engineers, and adequately prepare by acquiring the necessary science, technology, engineering and math (STEM) skills along with "soft" skills such as collaborative problem solving and communications. Access to equipment and financial resources along with encouragement from family, teachers and friends also contributes to students making it all the way through the pipeline.

The engineering guest speaker has a valuable opportunity to provide elementary school students with an early positive awareness of engineering and to encourage students to turn awareness into intent and pursue careers in engineering. All established engineers are encouraged to help recruit future engineers into the pipeline by developing effective speaking skills and seeking out opportunities to serve as guest speakers within the elementary school classroom.

\section{THE IMPORTANCE OF ENGINEERS SPEAKING WITH YOUNG STUDENTS}

The important contributions engineering guest speakers make towards recruiting future engineers are almost completely overlooked by the literature. This is due in large part to the informal, voluntary nature of guest speaking and the difficulty of measuring the degree of influence a guest speaker has on raising engineering awareness among elementary school students and on their intent to enter engineering degree programs. A review of literature on education outreach programs and career influencing factors for K-12 students provides strong evidence that the properly prepared guest engineering speaker makes a significant impact on recruiting future engineers by providing young students with an early awareness of engineering, serving as a positive engineering role model and encouraging students to pursue engineering careers.

\section{A. The Engineering Guest Speaker in the Elementary School Classroom Defined}

The engineering guest speaker is normally associated with at least one of the many engineering career fields and is invited to talk with elementary school students about subjects associated with engineering. Most guest speakers selflessly volunteer their own time and often have a child of their own in the elementary class with which they are speaking. Other engineers participate as guest speakers in a more formal manner through their organization's speakers bureau. These organizations include private companies, government agencies, and higher education facilities.

\section{B. Early Awareness of Engineering}

Early awareness of engineering careers and the positive impact engineers make on our world is essential for recruiting more "raw talent" into the engineering pipeline and maintaining the talent within the pipeline. Positive awareness of engineering careers at an early age allows more students to form an early intent to study engineering. It follows that an early intent to study engineering will more likely result in the student taking the appropriate courses to properly prepare for high school and an undergraduate degree in engineering. 
Studies indicate students start out enjoying math and science. As they progress through the years, they are less likely to enjoy math and science with a "dramatic drop in positive attitude toward science at the seventh grade level." Other research shows the drop off in interest around ninth grade. [2] "Many scientists and engineers say their career interest crystallized as early as elementary or junior high school, and most seem to make explicit choices before entry into high school.” [3]

"Carl Sagan (1989) commented that when he visited a kindergarten class he found himself in a class full of young scientists, who asked provocative, enlightening, insightful questions and who were clearly enthused and excited about science. But when he visited a high school class the students were much less interested. Somewhere between kindergarten and high school students have lost interest and enthusiasm in science." [2]

"Students need to be informed about what careers are available in science, math, and engineering, and what these professionals do on a daily basis. Students need to be exposed to all aspects of the field, rather than always keeping the focus on how hard the course of study will be in getting a degree in the math, science, and engineering field. Students need to know how science, math, and engineering personally relate to them and how they can use science, math, and engineering to change the world that they live in for the better." [4]

These studies underscore the need for more early positive awareness of engineering and science in the elementary school classroom. Currently, elementary school students have very little awareness or a distorted, negative awareness of the engineering profession. Pearlman and others suggest this insufficient exposure to careers in technology may explain, in part, the lack of commitment to careers in engineering by American youth [5]. They are unaware of what an engineer does, the fundamental difference between engineering and science, the wide variety of engineering career fields, or the positive impact engineers have on our society.

The guest engineer speaking to an elementary school audience (ages 6-11) is able to describe what engineering is and some of the many different jobs an engineer performs. Engineering is most simply defined as "the practical application of science and math." It's all about "bringing science (with the help of math) to life by creating practical, real-world things." [6] Just about everything created by humans was developed thanks to the work of engineers. This point is very useful as an introduction to describing the wide variety of engineering careers available.

\section{Positive Engineering Role Models}

Positive engineering role models are a strong influence on students' decisions to study science and engineering. Often, the engineering guest speaker is the first engineer these students meet in person, providing a crucial first impression of the engineering career field and a positive visual image of what an engineer really looks like. A strong visual image (or role model) of what an engineer really looks like helps young students mentally project themselves into the role of an engineer. This process of being able to visualize oneself in a particular career role is an influencing factor in choosing that career. [7]

Positive role models help instill self confidence and increase academic performance, especially in young women. One study noted "women who had female role models in high school were three times as likely to receive A's in their college mathematics courses." [2]

Engineering education experts frequently recommend increasing the number of positive engineering role models for K-12 students as a way of increasing the number of engineering graduates, especially women graduates. In 2004, a group of engineering education experts recommended creating more engineering role models. K-12 teachers, university professors, government and industry representatives came together during the ASEE Leadership Workshop on K-12 Engineering Outreach in Salt Lake City, UT to discuss ways to promote and enhance engineering education in K-12 classrooms. One of the six guidelines for improvement formulated by the group was: "Make Engineers "Cool": Outreach to urban schools and females more aggressively, and create more mentors and role models to attract these constituencies" [8]

Positive engineering role models help to "immunize" young students from adopting unflattering stereotypes of engineers frequently portrayed in the mass media. A survey of Silicon Valley, CA students indicated "sixty-six 
percent of students obtain career information from the mass media, a source that - according to outside research generally presents unflattering and unrealistic images of technology workers." [5]

Today, many young students develop an unflattering, stereotypical image of scientists and engineers based on movies, cartoons and other mass media. Amazingly, and unfortunately, this stereotypical image has not changed much over the past 50 years. Since many young students are unable to distinguish the difference between a scientist and an engineer, they typically apply many of the same negative stereotypes to both.

In a 1957 study, the views of about 35,000 high school students concerning what a scientist looks like were summarized. The study noted many common views, most negative, concerning a scientist: "The scientist is a man who wears a white coat and works in a laboratory. He is elderly or middle aged and wears glasses... He may be bald. He may wear a beard, may be unshaven and unkempt. He may be stooped and tired... He is surrounded by equipment: test tubes, Bunsen burners, flasks and bottles, a jungle gym of blown glass tubes and weird machines with dials... He spends his days doing experiments. He pours chemicals from one test tube into another... He experiments with plants and animals, cutting them apart, injecting serum into animals....His work is uninteresting, dull, monotonous, tedious, time consuming...He has no other interests and neglects his body for his mind...He has no social life, no other intellectual interests, no hobbies or relaxations. He bores his wife...He brings home work and also bugs and creepy things." [9]

Both male and female students almost always used the words "his" and "he" when describing the scientist. It's no wonder many uninformed young students, especially women, find these stereotypical images of a scientist unappealing.

In 1986, researchers at Harvard University's Educational Technology Center repeated the 1957 study listed above and found many of the same familiar stereotypes: "scientists are nerds and science is important but boring." [10] Also in 1986, Cheryl Mason obtained insight into middle school students' ideas of what a scientist looks like by using a "Draw-A-Scientist Test." An example, taken from her study and typical of most drawings generated, is shown in Figure 1.

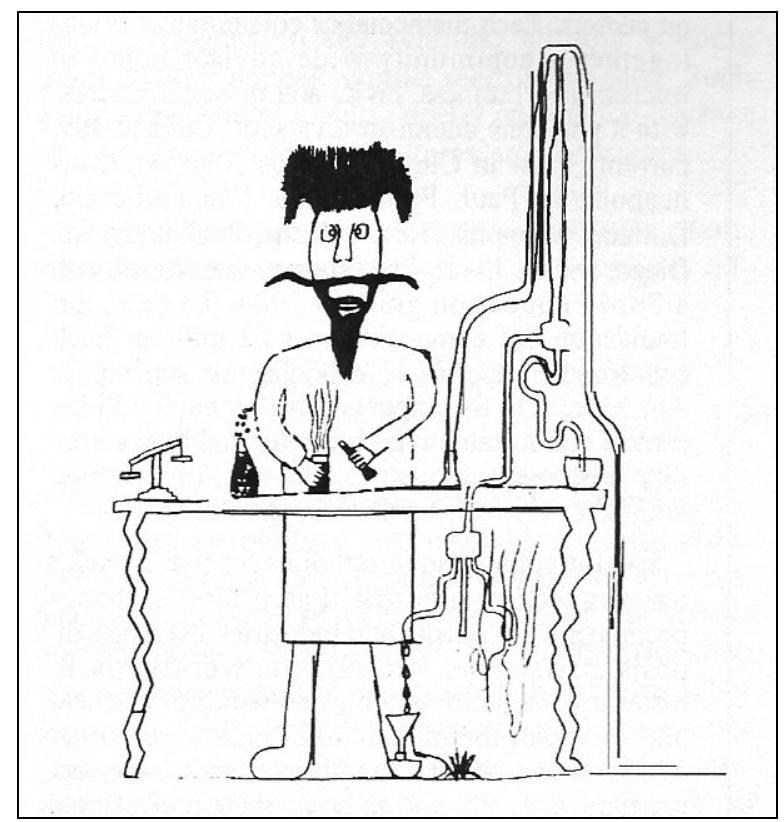

Figure 1 - 1986 drawing by middle school student in response to the question "What does a scientist look like?"

Most drawings indicated the same old male-centered stereotypes still remained: "the scientist is an elderly male, wearing a white coat and glasses and performing dangerous experiments." [11] 
In 2007, the unflattering scientist/engineer stereotype persists. For the past ten years, Jennifer Cook, a $6^{\text {th }}$ grade teacher in Blackfoot, Idaho has had her class complete the "Draw-A-Scientist Test." A typical drawing from 2007 is shown in Figure 2.

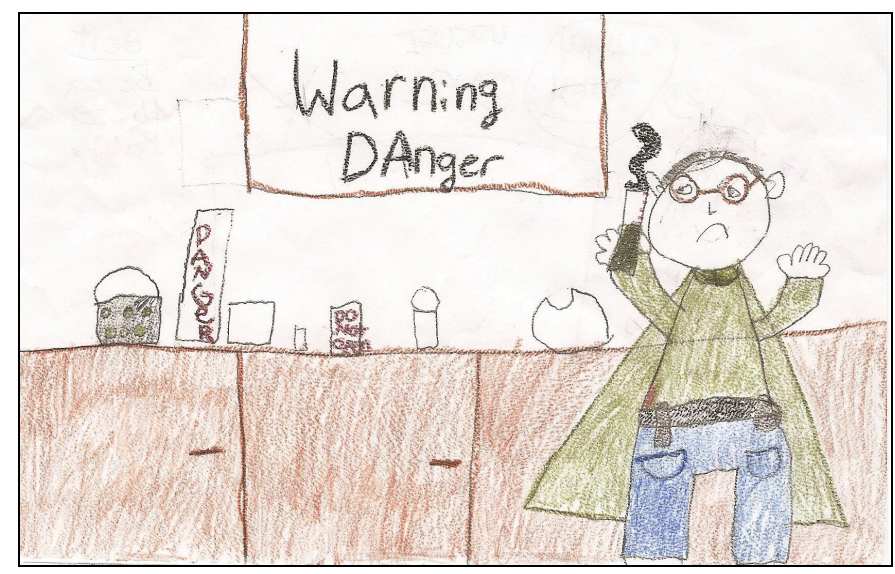

Figure 2 - 2007 drawing by $6^{\text {th }}$ grade student in response to the question "What does a scientist look like?"

A comparison between the 1986 drawing and the 2007 drawing shows once again, many similar and unflattering stereotypes: "the scientist is not smiling, the scientist is an older male, the scientist is indoors, he's wearing a lab coat, and there are test tubes and other laboratory items present. His work is dangerous."

In the image studies listed above, the students almost always portray the scientist as a man, creating a gender conflict for young women trying to visualize themselves as a scientist or engineer. Ms Cook reinforced this point in an interview by stating over the past 10 years in which she has conducted the "Draw-A-Scientist Test", her classes have remained roughly $48 \%$ male and $52 \%$ female, yet $90 \%$ of the drawings show the scientist as a male. [12]

These stereotypes are potent and persistent. They affect a student's decision about taking engineering courses and pursuing an engineering career. This holds true especially for women. The best defense against students developing these stereotypical ideas of engineers is to provide them with many positive role models or images of real engineers at an early age. The properly prepared engineering guest speaker presenting to an elementary school audience can do a great deal of good toward eliminating the negative engineering stereotype.

The topics on which guest engineers speak are as varied as the career fields in which they work. Regardless of the topic presented, the engineering guest speaker should always remember her speaking opportunity puts her in a valuable position to raise awareness of the many careers in engineering and the valuable contributions engineers make in our quality of life. She may also combat negative engineering stereotypes through serving as a positive engineering role model and encourage students to consider engineering by showing a genuine passion for the profession.

The following section provides guest speakers with some "tried and true" best practices techniques for effectively communicating with young audiences and presenting themselves as positive engineering role models.

The author developed these best practice techniques over the past 10 years while serving as the lead volunteer engineering guest speaker for the U.S. Department of Energy, Idaho National Laboratory's Speakers Bureau.

\section{BEST PRACTICE TECHNIQUES FOR SPEAKING WITH YOUNG STUDENTS}

In this section, differences between speaking with young audiences compared to adult audiences are examined and several best practice techniques are presented to help the engineering guest speaker prepare and deliver a positive and dynamic presentation for young audiences. 


\section{A. Differences in Speaking with Young Audiences versus Adult Audiences}

Preparing for and speaking with a group of young students is the same in many ways as with adults. The engineering guest speaker should be familiar with the topic presented, understand the type of audience he is presenting to, organize the material in a sequence that clearly leads the audience from one topic to the next, thoroughly practice the presentation, and use well prepared, meaningful visual aids and demonstrations to help increase the audience's understanding of the material presented.

There are differences between an elementary school age audience and an adult audience. Some of these differences make speaking with a young audience more challenging while other differences, if understood by the guest speaker, make speaking with a young audience easier (and more fun). The main challenge a guest speaker faces when presenting to a young audience is the audience's lack of knowledge concerning the engineering profession. In fact, chances are, most of the young audience members have no idea what an engineer is. Or worse, they have a negative misconception based on typical stereotypes portrayed in popular media. Terms and phrases engineers frequently use with one another will be lost on a young audience. Visual aides and demonstrations must be considered with a critical eye to ensure they are presented without any assumption of engineering knowledge.

On the plus side, young audiences are often much less reserved compared to adult audiences and are still easily caught up in the joy of learning something new. Elementary school students will readily volunteer to participate in demonstrations, ask questions in front of their peers, and give clear signals, through body language, indicating whether they are engaged in the presentation or not. This last point of "visual feedback" helps a speaker know when he is losing his audience during a particular topic or if he has the audience completely engaged in what is being presented. By paying close attention to these visual feedback cues, the engineering guest speaker can make immediate changes during his presentation and quickly learn what parts of a presentation should be modified or eliminated before giving the presentation again. Engineers understand the importance of feedback for optimizing electrical and mechanical systems. In the case of public speaking, these visual feedback cues are just as important for optimizing presentation technique and content. Young audiences will always provide much more of this valuable feedback than will adult audiences.

By understanding these differences, the engineering guest speaker can greatly improve the content of her presentation and her speaking technique for young audiences, resulting in a lasting, positive image of engineers and the engineering profession.

\section{B. Best Practice Techniques for Speaking With Young Audiences}

The best practice techniques listed below apply to young audiences. The general concepts behind many of the techniques listed are part of the common knowledge for public speaking technique, while the details for each best practice technique have been refined by the author during the past several years as an engineering guest speaker for the Idaho National Laboratory's Speakers Bureau. These best practice techniques will certainly help a guest speaker effectively present engineering topics to a young audience. The primary intent for providing these techniques, however, is to help the guest engineering speaker increase her ability to serve as a positive role model for the engineering profession and to instill within young students a simple understanding, interest and appreciation for the engineering profession, ultimately leading to a higher likelihood these students will pursue degrees in engineering.

The first five best practice techniques focus on improving a guest speaker's presentation method while the last five techniques address improving presentation content.

1) Communicate using unique style: Young audiences are quite good at sensing if a speaker is not being genuine and their respect for the speaker will diminish. Diminished respect equates to a diminished ability to serve as a positive engineering role model. The speaker should avoid emulating his audience in an attempt to gain acceptance. Dress, words and actions should all be considered with the aim of projecting a relaxed, self-confident, image of an adult, the type of adult young audience members may want to become. The speaker needs to understand the prevailing unflattering engineering stereotypes and avoid promoting them further. The remaining best practice techniques are most effective when the engineering guest speaker uses them in a manner that supports his own style of speaking. 
2) Speak on familiar topics: The speaker should pick topics with which he is familiar and has a genuine interest. This genuine interest in the topic presented will translate to the young audience as the speaker having a genuine interest in engineering. To serve as an effective engineering role model and create positive awareness of engineering, the speaker must leave no doubt of his own interest and enthusiasm for engineering. A familiar topic will allow the speaker to more easily present his topic without having to constantly refer to notes or a script resulting in a more dynamic, confident presentation. Self confidence is one of the most important characteristics for an effective role model. The need to constantly look at notes makes the guest speaker seem less confident. Familiarity with the topic also allows the speaker to more easily improvise during the presentation when demonstrations go awry or when an audience member acts out unexpectedly, two things that occur frequently when combining engineering presentations and young audiences.

3) Speak at a level appropriate for the audience: This is often a difficult point for many engineers. Engineers, like professionals in other fields, use a unique collection of jargon, all of which means absolutely nothing to an elementary school student. The speaker should use simple language, void of "technical speak", while enthusiastically presenting her topic. Unfamiliar and "big" words tend to leave young audience members confused and frustrated. It's important to remember the speaker is probably the first exposure to engineering for the young audience. If the audience is confused and frustrated, they might possibly attribute these negative feelings to the field of engineering in general in which case the speaker will create a negative impact on recruiting future engineers. Speaking at a level appropriate for young audiences does not mean the speaker should patronize, use condescending speech or talk down to the audience. This is very insulting and a speaker will quickly lose the respect of her audience. The speaker should frequently watch the audience closely for signs of visual feedback to determine if she is communicating in simple enough terms without talking down or coming across as condescending.

4) Show enthusiasm: Elementary school audiences are not concerned with engineering formulas or facts. They probably won't remember any of the details presented. What they most likely will remember is the speaker's enthusiasm while talking about engineering. When practical, the speaker should enthusiastically describe how her own work in engineering makes the world a better place. An audience will forgive mistakes made by the speaker if the speaker is presenting with enthusiasm and passion. Enthusiasm is contagious, especially for a young audience. A blasé style of speaking will typically leave the audience with a blasé memory of the topic.

5) Acknowledge and show respect for audience members: By showing respect for audience members, the speaker will help build the students' self-esteem and gain their respect, resulting in the speaker serving as a more effective engineering role model. The speaker should acknowledge audience members by using their names whenever possible. If a student is asking a question or volunteering to help with a demonstration, the guest speaker should make a point of asking the student's name and then repeating it to the audience. Everybody likes to hear their name. Young audience members thrive on recognition. Building rapport with a young audience will help the speaker gain the audience's respect and trust. The speaker can build rapport with a young audience by making eye contact and smiling, chatting with students as they file into the room, treating every question, even the "crazy" ones, as important and providing honest answers.

6) Start the presentation with a dynamic demonstration using volunteers on stage: This is a very effective technique for capturing the attention of young audiences. The younger the audience, the more effective this technique is. This method works well because young students want to see what is going to happen to their classmates. Young audiences are very peer oriented and will more likely engage in the presentation if one of their friends takes part in the demonstration. The demonstration needs to tie in with the topic presented or the audience will quickly become sidetracked. It is very important the speaker avoids embarrassing volunteers and treats them with respect. A student should never be forced to "volunteer" in a demonstration. The first use of audience participation is critical for encouraging more volunteers later in the talk. As stated earlier, young audience members thrive on recognition. If the speaker acknowledges volunteers by name, treats them respectfully and publicly praises them for their participation, he will have no problem encouraging additional volunteers. In fact, students may become so eager to volunteer; he might have a problem with students becoming disappointed if not selected to participate. Audience participation in a demonstration reinforces in the mind of the audience that engineering involves interaction and teamwork. Figure 3 shows a brave elementary school volunteer sitting in the "electromagnetic-seat-of-science" while her teacher and the author suspend her several inches above the floor during a demonstration on how electromagnets work. 


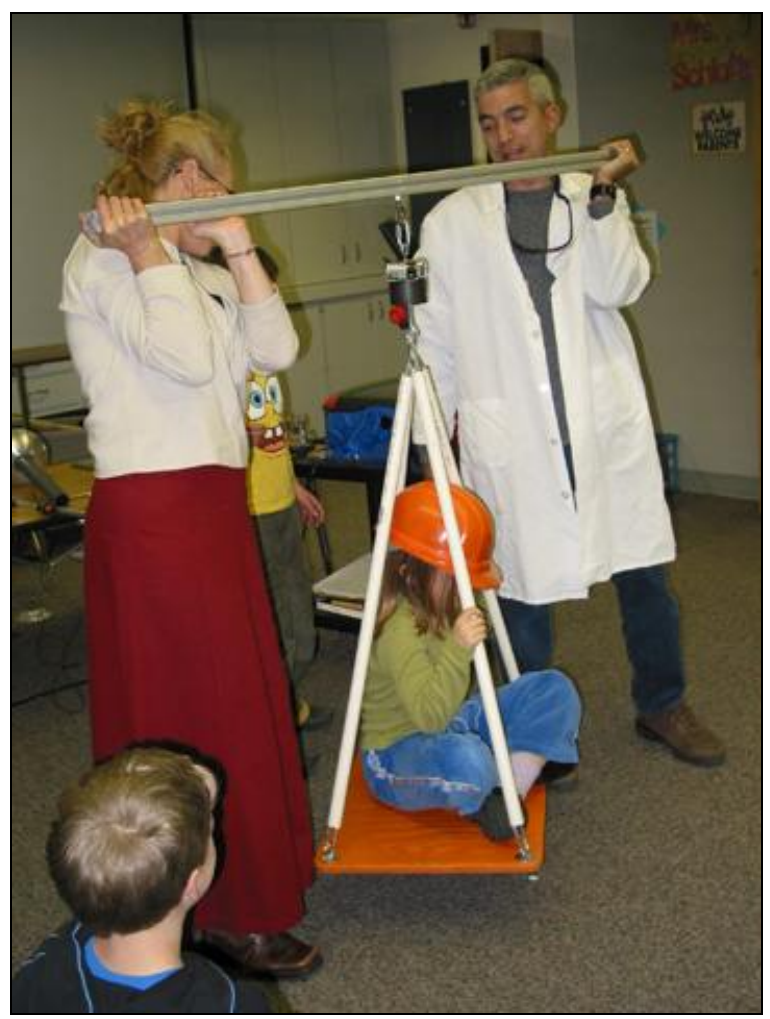

Figure 3 - A young audience member helps demonstrate the powers of an electromagnet

7) Design the presentation to be more like a "show": Suspense, humor, irony, foreshadowing, motion, silence and good stage presence are all techniques that engage an audience and help create a positive, emotional memory related to the topic and presenter. Humor is so important it is listed separately. These techniques require additional effort and much practice for a beginning speaker to become proficient using. The results are well worth the efforts. When used effectively, these techniques in showmanship will help the engineering guest speaker deliver a dynamic and entertaining presentation that leaves a positive and lasting impression of engineering on students with the hopes of influencing their future decisions to pursue careers in engineering.

8) Use appropriate humor whenever possible: Humor, more than any other technique, will quickly endear a guest speaker to their young audience. It is a characteristic both young and old admire in a speaker (and role model). In addition, humor helps a nervous speaker get started. According to Tom Anton, an expert in public speaking, humor helps the speaker do the following:

- Connect with the audience

- Keep attention

- Emphasize points and ideas

- Disarm hostility

- Make information more memorable

- Make a positive impression

Humor is a very effective tool for winning over the hearts and minds of young audience members but like all speaking techniques must be used properly or it has the potential for backfiring. Never make an audience member the butt of a joke. Avoid negative humor and sarcasm altogether. These forms of humor detract from the image of a positive role model. Don't use humor for the sake of humor alone. It should be tied somehow to the presentation. After making a point using humor, the speaker should restate the point without humor. 
Using self-effacing humor, or making fun of oneself, has many positive effects. It lets the audience think the speaker is not superior to the audience. It helps the audience perceive the speaker as self-confident, secure, likeable and not afraid to fail. These are very important characteristics in a positive engineering role model. The use of selfeffacing humor by engineering guest speakers also helps counter two of the more common negative engineering stereotypes; that is, engineers are too serious and they don't have a sense of humor. The speaker should be careful not to overdo self-effacing humor. Too much will leave the audience with the perception that the speaker has low self esteem.

9) Tie in "real-world" engineering examples: Prior to their presentation, the engineering guest speaker should talk with the teacher, understand the content of the current curriculum being taught and discuss ways of linking the curriculum to "real-world" examples from the speaker's career. Even though most elementary school teachers typically have a limited education in engineering and are eager to have career engineers speak with their students, the engineering guest speaker must keep in mind she is a guest speaker, not THE teacher. By talking with the teacher ahead of time to coordinate presentation points with current curriculum, the speaker will more likely gain the trust and respect of the teacher and be asked back for future speaking engagements. The speaker should always try using examples that create a vivid mental image of what an engineer does. Real-world examples help young students understand what an engineer actually does allowing them to visualize themselves in the role.

10) Keep visual aides and props simple yet dynamic: Visual aides and props are great attention getting devices, especially for young audiences. They need to be carefully planned out and practiced to avoid bogging down a presentation. If the speaker uses overhead or projected visuals, he should make sure the visual is, for the most part, self explanatory and clearly supports the topic presented. The use of photos and other images is encouraged. The use of words, other than simple titles, should be avoided. Wordy visuals will detract from what the speaker is actually saying and most young audiences won't read them anyway. For young audiences, color photos and slides are much more attention getting than black and white.

Audience safety is extremely important when conducting any type of demonstration, especially if volunteers are involved. The speaker must think ahead, consider possible adverse consequences of unusual interactions with the audience and carefully prepare for everything to go smoothly. If using a Van de Graaff generator, do any students or teachers have pacemakers? If using rubber gloves or balloons are there audience members with sensitivities to Latex? The speaker must be aware of all hazards associated with his presentation and vigorously apply measures to prevent the hazard from resulting in an injury. If there is any question at all that a hazard associated with a demonstration can not be completely mitigated, the speaker should not perform the demonstration. The details of any potentially hazardous demonstrations must be discussed in advance with the teacher prior to the presentation.

Design demonstrations to be simple and dynamic. When designing demonstrations use common objects whenever possible. Not only will this reduce the cost of preparing the demonstration, but it will also help a young audience relate to and remember the demonstration by providing an image they are familiar with. When a choice exists, pick an object that has some humor associated with it. If a demonstration requires the use of a balloon, consider using a rubber glove. They look funny when inflated. Figure 4 shows photos from a demonstration on how loudspeakers work. The demonstration used colorful plastic beads and music familiar to the age of the audience. Suspense and a calculated surprise were also designed into the demonstration.

Practice using props and conducting demonstrations many times before using them in a "live" presentation. Whenever possible, try out the demonstration on a few young kids before using it in front of an entire elementary school class. Be ready for when a demonstration does not go as planned. This will inevitably happen once in a while no matter how carefully the speaker prepares. If a demonstration is not working don't spend too much time trying to fix the problem. Simply move on.

The above best practice techniques focus more on "what to do" and not so much on "how to do it". There are many books and other resources dedicated to describing the "how-to" of effective speaking. The next section provides the engineering guest speaker with a list of resources for learning how to improve his presentation style and develop effective presentation content. The list given is by no means all inclusive. It represents a subset of the author's favorite sources for helping engineering guest speakers deliver an exciting presentation, present themselves as positive engineering role models and encourage young students to pursue careers in engineering. 


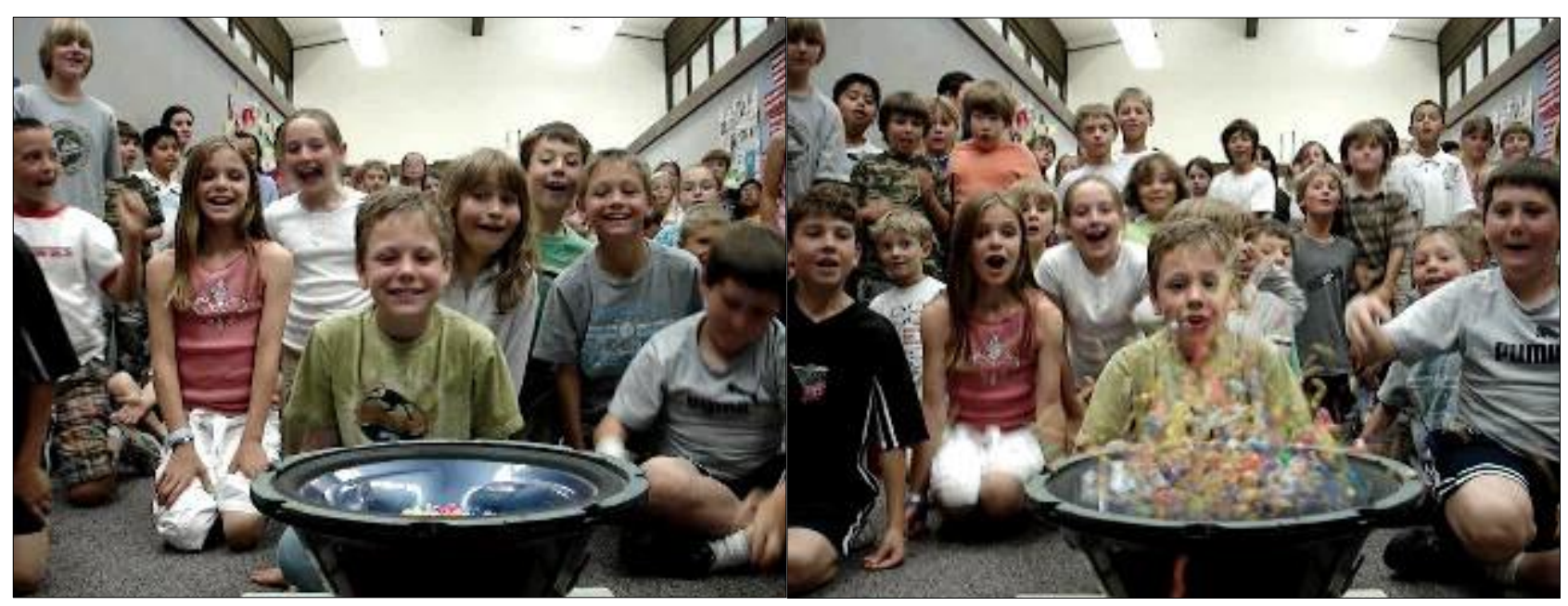

Figure 4 - Elementary school students learn how a loudspeaker works

\section{INFORMATION FOR GETTING STARTED AS AN ENGINEERING GUEST SPEAKER}

As an engineer, there are many opportunities to get involved with guest speaking at the elementary school level. If the engineer has a young child, she can start by meeting with her teacher and volunteering to give a presentation on engineering to the class. Many organizations support formal engineering awareness programs in which employees are encouraged to participate. Schools often sponsor career days in which engineering guest speakers may participate. Regardless of where the speaking opportunity exists, the most important step in becoming an engineering guest speaker is to commit to that first talk. The effort and time required to develop a talk is typically never easy to find. Most engineers, contrary to the stereotype, have active lives outside of work in addition to a busy career. Finding time to prepare for and devote to guest speaking takes sacrifice. Once the upfront effort of creating and practicing a dynamic and enthusiastic presentation is complete, subsequent presentations will require much less preparation. Speaking with elementary school students can be very gratifying too. Many speakers experience a euphoria associated with knowing they have successfully engaged an entire young audience and generated excitement and awareness about engineering.

The following resources will help the engineering guest speaker raise awareness of engineering and encourage more students to pursue careers in engineering by providing the information necessary to develop an effective presentation.

\section{A. Resources for Improving Speaking Technique}

These resources provide excellent tips and techniques for developing the skill of public speaking. Many provide specific techniques for speaking with young audiences.

- Toastmasters International - http://www.toastmasters.org/

Toastmasters International is a world leader in helping people become more competent and comfortable in front of an audience. The nonprofit organization now has nearly 220,000 members in 11,300 clubs in 90 countries, offering a proven and enjoyable way to practice and hone communication and leadership skills. The website provides many useful tips for overcoming stage fright and developing effective presentations. Engineers serious about improving their speaking skills should consider joining and attending weekly meetings in which participants practice and learn skills by filling a meeting role, ranging from giving a prepared speech or an impromptu one to serving as timer, evaluator or grammarian. 
- National Speakers Association - http://www.nsaspeaker.org/

National Speakers Association is the leading educational and networking organization for professional speakers! NSA is a national not-for-profit association with thousands of members across the United States.

- Advanced Public Speaking Institute - http://www.public-speaking.org/

This website provides a free list of great tips for public speaking. The author frequently uses many of these tips when presenting.

- Checklist for a Good Speaker - http://www.angelfire.com/ab/speakers/checklist.htm/

This is a simple checklist that covers the essential basics of effective speaking technique.

- The Art of Using Humor in Public Speaking - $\mathrm{http} / /$ www.squaresail.com/auh.html

This site provides very good information from Anthony L. Audrieth on how to use humor when presenting. The information is complete with some excellent examples.

\section{B. Resources for Developing Presentation Content}

These resources provide ideas and complete lesson plans for developing exciting content for speaking on a variety of engineering topics. Several of the sites also contain extensive information on careers in engineering, examples of how engineering is applied, the positive benefits of engineering and ways of presenting engineering to young audiences.

- NASA Quest - http://quest.arc.nasa.gov/

NASA Quest offers a wide range of FREE online tools and resources for teachers, students, parents and others including Web and print lesson plans, educator guides and workbooks.

- $\quad$ ASEE Engineering K12 Center - $\underline{\text { http://www.engineeringk12.org }}$

The ASEE EngineeringK12 Center seeks to identify and gather in one place the most effective engineering education resources available to the K-12 community. From comprehensive data on outreach programs to career guidance materials to hundreds of links and readings related to engineering education, the ASEE EngineeringK 12 Center offers immediately useful, easily accessible materials tailored to all parties with an interest in engineering education.

- Discover Engineering Online - http://www.discoverengineering.org/

Teachers, students and others built Discover Engineering Online to promote the engineering profession as a career choice among young people and to recognize the accomplishments of the world's engineers. This site is excellent for learning about the many different types of engineering career fields.

- Discovery Lesson Plans Library - http://school.discoveryeducation.com/lessonplans/

View lesson plans for elementary, middle and high school students. Find hundreds of original lesson plans, all written by teachers for teachers. Many of these lesson plans convert easily to presentation demonstrations.

- Try Engineering - http://www.tryengineering.org/home.php 
Developed by IEEE, this site is designed for young students, teachers and parents, giving information on engineering careers and engineering activities the guest speaker can use to prepare a dynamic and informative presentation.

\section{DISCUSSION}

The properly prepared engineering guest speaker performs a critical role in recruiting future engineers. By learning to become a better speaker, she becomes more effective in raising awareness of engineering and serves as a positive engineering role model resulting in a positive first impression of engineering for many young students. Increasing the number of young students who receive a positive image of engineers and engineering careers will ultimately lead to more future engineers. The potential for engineering guest speakers to reach a large number of elementary students is great. A quick look at some statistics makes this evident.

According to 2004 statistics from the U.S. Department of Labor and U.S. Department of Education, there were 1.4 million engineers and 1.5 million elementary (grades 1-6) school teachers employed in the United States. In the fall of 2004, there were 21.8 million elementary school students enrolled in both public and private schools across the United States. If just 2 out of every 10 engineers made the effort to properly prepare for and serve as a guest engineering speaker at the elementary school level and, if these engineers presented 3 talks that year to an average class size of 20 students, 16.8 million students, or over $75 \%$ of all U.S. elementary school students for 2004 would have received first-hand exposure to a positive engineering role model, and heard first-hand about what an engineer does, how they do it and the positive impact engineering has on everyday life.

Developing a multimedia resource (DVD or on-line course) specifically geared towards providing the engineering guest speaker with information on how to effectively raise awareness of and promote interest in engineering careers while speaking with elementary school audiences would serve as a cost effective method for increasing the number of future engineers.

Young students who have experienced a positive interaction with an engineer are more likely to pursue a career in engineering. Effective guest speaking by engineers in elementary school classrooms today will increase the likelihood these young students will become the desperately needed engineers of our future. 


\section{REFERENCES}

[1] Committee on Prospering in the Global Economy of the 21st Century: An Agenda for American Science and Technology, National Academy of Sciences, National Academy of Engineering, Institute of Medicine. (2006). Rising Above The Gathering Storm: Energizing and Employing America for a Brighter Economic Future. National Academy of Sciences.

[2] Astin, A., \& Astin, H. (1992). Undergraduate science education: the impact of different college environments on the educational pipeline in the sciences. Washington, DC: National Science Foundation. (ERIC Document Reproduction Service No. ED 362 404)

[3] U.S. Congress, Office of Technology Assessment. (1988). Educating Scientists and Engineers: Grade School to Grad School. OTA-SET-377 (Washington, DC: U.S. Government Printing Office, June 1988).

[4] Jones, M. M. \& Williamsburg, V. (2005). Creating Future Scientists and Engineers: K-12 Outreach that Works. Collen O'Shea School of Education, Curriculum and Instruction, College of William and Mary.

[5] Kearney, A. T. (2002). 2002 Workforce Study. Silicon Valley Joint Venture

[6] Engineers Dedicated to a Better Tomorrow (2007). Answering Your Common Questions About Engineering and Engineers. [Online] Avalable: http://www.dedicatedengineers.org/Resources/QA on Engineering.pdf

[September 2007]

[7] CHEN, C. P. (1997). Career Projection: narrative in context, Journal of Vocational Education and Training, Vol. 49, No. 2, 311-326.

[8] Douglas, J., Iverson, E., \& Kalyandurg C. (2004). Engineering in the $k$-12 classroom: an analysis of current practices and guidelines for the future. Washington, DC: The American Society of Engineering Education (ASEE) Engineering k12 Center.

[9] Mead, M. \& Metraux, R. (1957). Images of the Scientists Among High School Students. Science, vol. 126, Aug. 30, 1957, p. 384-390.

[10] Harvard University Educational Technology Center. (1988). Why Do Few Students Want to Become Scientists?. Harvard Education Letter, vol. 4, No. 1, January 1988, p. 6

[11] Mason, C. L. (1986). Student Attitudes Toward Science and Science-Related Careers: An Investigation of the Efficacy of a High School Biology Teacher Intervention Program. Unpublished doctoral dissertation, Perdue University, 1986.

[12] Cook, J. (2007). Interview with Jennifer Cook. Teacher at Blackfoot $6^{\text {th }}$ Grade School. Blackfoot, Idaho. September 17, 2007.

\section{AUTHOR BIOGRAPHY}

Kevin L. Young is an electrical engineer for the Department of Energy, Idaho National Laboratory. He received a B.S. in Electrical Engineering from Utah State University in 1987 and an M.S. in Electrical Engineering from the University of Idaho in 2000. He is a member of the American Society for Engineering Education (ASEE) and a senior member of the Institute of Electrical and Electronics Engineers (IEEE). He has been involved with engineering awareness outreach for the past ten years, conducting presentations on engineering to elementary school audiences all over the State of Idaho. He currently serves as the lead volunteer speaker for the Idaho National Laboratory Speakers Bureau and helps instruct new speakers on techniques for giving effective presentations. He is an engineer who smiles a lot, is extroverted, does not take himself too seriously and has several interests outside of engineering, including playing sax in his semi-professional jazz quartet. 